\title{
Magnetic core-shell nanowires as MRI contrast agents for cell tracking
}

\author{
Aldo Isaac Martínez-Banderas ${ }^{1 \dagger}$, Antonio Aires ${ }^{2 \dagger}$, Sandra Plaza-García², Lorena Colás², Julián A. Moreno³, \\ Timothy Ravasi ${ }^{1}$, Jasmeen S. Merzaban ${ }^{1}$, Pedro Ramos-Cabrer ${ }^{2,4^{*}}$, Aitziber L. Cortajarena ${ }^{2,4,5^{*}}$ and Jürgen Kosel ${ }^{3^{*}}$
}

\begin{abstract}
Background: Identifying the precise location of cells and their migration dynamics is of utmost importance for achieving the therapeutic potential of cells after implantation into a host. Magnetic resonance imaging is a suitable, non-invasive technique for cell monitoring when used in combination with contrast agents.

Results: This work shows that nanowires with an iron core and an iron oxide shell are excellent materials for this application, due to their customizable magnetic properties and biocompatibility. The longitudinal and transverse magnetic relaxivities of the core-shell nanowires were evaluated at $1.5 \mathrm{~T}$, revealing a high performance as $\mathrm{T}_{2}$ contrast agents. Different levels of oxidation and various surface coatings were tested at $7 \mathrm{~T}$. Their effects on the $\mathrm{T}_{2}$ contrast were reflected in the tailored transverse relaxivities. Finally, the detection of nanowire-labeled breast cancer cells was demonstrated in $\mathrm{T}_{2}$-weighted images of cells implanted in both, in vitro in tissue-mimicking phantoms and in vivo in mouse brain. Labeling the cells with a nanowire concentration of $0.8 \mu \mathrm{g}$ of Fe/mL allowed the detection of $25 \mathrm{cell} / \mathrm{s} / \mathrm{L}$ in vitro, diminishing the possibility of side effects. This performance enabled an efficient labelling for high-resolution cell detection after in vivo implantation ( 10 nanowire-labeled cells) over a minimum of 40 days.
\end{abstract}

Conclusions: Iron-iron oxide core-shell nanowires enabled the efficient and longitudinal cellular detection through magnetic resonance imaging acting as $T_{2}$ contrast agents. Combined with the possibility of magnetic guidance as well as triggering of cellular responses, for instance by the recently discovered strong photothermal response, opens the door to new horizons in cell therapy and make iron-iron oxide core-shell nanowires a promising theranostic platform.

Keywords: Cell tracking, Magnetic resonance imaging, Iron-iron oxide, Core-shell, Nanowires, Cell labeling, $T_{2}$ contrast

\footnotetext{
*Correspondence: pramos@cicbiomagune.es; alcortajarena@cicbiomagune. es; jurgen.kosel@kaust.edu.sa

${ }^{+}$Aldo Isaac Martínez-Banderas and Antonio Aires contributed equally to this work

${ }^{2}$ Center for Cooperative Research in Biomaterials (CIC biomaGUNE), Basque Research and Technology Alliance (BRTA), Paseo de Miramon 182, 20014 Donostia San Sebastián, Spain

${ }^{3}$ Division of Computer, Electrical and Mathematical Sciences and Engineering, King Abdullah University of Science and Technology, Thuwal, Jeddah 23955-6900, Saudi Arabia

Full list of author information is available at the end of the article
}

\begin{abstract}
Background
Over the last years, nanomaterials have been widely investigated for improving the diagnosis of diseases and their treatments [1]. Thanks to their structural, chemical, optical or mechanical properties, nanomaterials provide the ability to interact with cells in different ways and with remote control mechanisms [2-4]. Due to the importance of a very early-stage detection of disease, biomedical imaging has become an invaluable tool for both scientific and clinical applications [5]. In particular, magnetic resonance imaging (MRI) is a powerful tool, allowing the non-invasive and real-time monitoring of
\end{abstract}

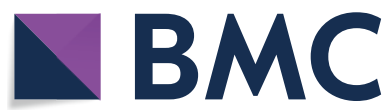

(c) The Author(s) 2020. This article is licensed under a Creative Commons Attribution 4.0 International License, which permits use, sharing, adaptation, distribution and reproduction in any medium or format, as long as you give appropriate credit to the original author(s) and the source, provide a link to the Creative Commons licence, and indicate if changes were made. The images or other third party material in this article are included in the article's Creative Commons licence, unless indicated otherwise in a credit line to the material. If material is not included in the article's Creative Commons licence and your intended use is not permitted by statutory regulation or exceeds the permitted use, you will need to obtain permission directly from the copyright holder. To view a copy of this licence, visit http://creativeco mmons.org/licenses/by/4.0/. The Creative Commons Public Domain Dedication waiver (http://creativecommons.org/publicdomain/ zero/1.0/) applies to the data made available in this article, unless otherwise stated in a credit line to the data. 
dynamic processes in living cells and organisms. Contrast agents (CAs) are often utilized in MRI, to better discern tissues of similar magnetic properties, by shortening the transversal $\left(\mathrm{T}_{2}\right)$ and/or the longitudinal $\left(\mathrm{T}_{1}\right)$ relaxation times of the nearby water protons at the region of interest $[6,7]$. Commercially available $\mathrm{T}_{1}$ CAs are paramagnetic complexes, usually gadolinium $\left(\mathrm{Gd}^{3+}\right)$ chelates [8], while $\mathrm{T}_{2}$ CAs are mostly based on iron oxide $\left(\mathrm{Fe}_{\mathrm{x}} \mathrm{O}_{\mathrm{y}}\right)$ nanoparticles (NPs) $[9,10] . \mathrm{Fe}_{\mathrm{x}} \mathrm{O}_{\mathrm{y}} \mathrm{NPs}$ are superparamagnetic and exhibit a magnetization proportional to an external magnetic field, which generates local magnetic field inhomogeneities and accelerates the dephasing of the surrounding protons' spins [7]. Limitations such as the passive accumulation of $\mathrm{Fe}_{\mathrm{x}} \mathrm{O}_{\mathrm{y}} \mathrm{NPs}$ in the liver and spleen $[11,12]$ together with signal attenuation (low signal-tonoise ratio) [13, 14], strong blooming effect [15], and high background interference (low specificity) [16] have restricted their clinical application [17-19]. Nevertheless, $\mathrm{T}_{2}$ CAs are highly appreciated for research purposes in relevant applications such as cell tracking studies [20]. Besides, a new generation of particles is being developed to tackle the previously encountered issues [21,22] and functionalities are dramatically expanded by imaging and guiding the particles, i.e. magnetic resonance navigation [23]. In order to be an efficient $\mathrm{T}_{2} \mathrm{CA}$, a nanomaterial should possess a large transversal magnetic relaxivity constant, $r_{2}$, which is proportional to the effective magnetic moment of the material [24]. This requirement places nanowires (NWs) composed of iron $(\mathrm{Fe})$ in a prime position, due to their high saturation and remanent magnetization values, the latter originating from the strong shape anisotropy $[25,26]$. NWs can be grown in nanoporous templates by electrochemical deposition, which is a simple and efficient method that provides accurate control of the length and diameter [27-29].

Previously, the performance of Fe-based NWs and multisegmented Fe/gold NWs was assessed, where both types of NWs appeared to be promising $\mathrm{T}_{2}$ CAs [30]. Similarly, an aqueous suspension of coated nickel NWs exhibited good performance for $T_{2}$ contrast with $r_{2}$ values similar to those of commercial $\mathrm{Fe}_{\mathrm{x}} \mathrm{O}_{\mathrm{y}} \mathrm{NPs}$ [31]. However, genotoxicity and cytotoxicity effects have been reported in nickel-containing particles [32].

In this paper, we investigate the performance of $\mathrm{Fe}-$ $\mathrm{Fe}_{\mathrm{x}} \mathrm{O}_{\mathrm{y}}$ core-shell NWs as tunable $\mathrm{T}_{2}$ CAs. We utilize them for MRI cell tracking, which is a rapidly advancing medical method since the earliest studies of stem cell detection [33-35]. In order to employ the therapeutic potential of cells, their precise location, and the dynamics of their migration and differentiation after implantation into the host must be monitored and understood. $\mathrm{Fe}_{\mathrm{x}} \mathrm{O}_{\mathrm{y}}$-based nanomaterials are among the most used systems for labeling of cells for in vivo tracking experiments
$[20,34,36]$. One of the key aspects of cell tracking studies is the sensitivity to detect a small number of cells after implantation. For this task, the strong magnetization [37] and biocompatibility [38-40] of $\mathrm{Fe}-\mathrm{Fe}_{\mathrm{x}} \mathrm{O}_{\mathrm{y}}$ core-shell NWs are foreseen as advantageous characteristics.

In this work, we studied the actuation of $\mathrm{Fe}-\mathrm{Fe}_{\mathrm{x}} \mathrm{O}_{\mathrm{y}}$ core-shell NWs for $\mathrm{T}_{2}$ contrast at representative clinical $(1.5 \mathrm{~T})$ and preclinical $(7 \mathrm{~T})$ fields, and at a different level of oxidation, and surface coatings. The amount of NWs interacting with the cells was spectrometrically quantified and the labeling sensitivity was assessed by in vitro $\mathrm{T}_{2}$-weighted images of the cells embedded in an agar gel. In vivo MRI cell tracking studies were carried out at 11.7 T, implanting the labeled cells into mouse brains.

\section{Results and discussion}

\section{Nanowire characterization}

NWs composed by Fe were produced with an average diameter of 30 to $40 \mathrm{~nm}$ and an average length of $0.7 \pm 0.16 \mu \mathrm{m}(\mathrm{n}=100)$, as illustrated in Fig. 1a, b. Since NWs are exposed to air, water, sodium hydroxide, ethanol, etc., oxidation of their surface is unavoidable. The oxidation creates core-shell NWs with an oxide layer that is typically $4-10 \mathrm{~nm}$ thick [39] composed of mainly $\mathrm{Fe}_{2} \mathrm{O}_{3}$ and $\mathrm{Fe}_{3} \mathrm{O}_{4}[37,40]$, and has a significant contribution to the biocompatibility [37], functionalizability, and magnetic properties of the NWs [39-43]. The electron energy loss spectroscopy (EELS) composition map in Fig. 1c confirms a core-shell structure with an Fe core (red color) surrounded by an FexOy shell (blue color).

In order to increase the thickness of the oxidation shell and thereby reduce the Fe core, a sample of NWs was subjected to oxidizing conditions (NWs_oxidized). The level of oxidation was evaluated by scanning transmission electron microscopy (STEM) and EELS in NWs that were placed in oxidizing conditions, and NWs that remained in ethanol all the time at room temperature. In both cases, the average relative concentrations of oxygen and Fe were measured in a specific region of different single NWs (Additional file 1: Figure S1) showing a mix between both elements in the oxidized shell and Fe in the core, (Additional file 1: Table S1, $\mathrm{n}=3$ for each condition). The oxygen/Fe ratio indicates the change in the thickness of the oxidation layer, which was then expressed as the percentage of oxygen and Fe in each NW analyzed. The average percentage of oxygen was found to be $33.7 \pm 7 \%$ for the treated NWs and $17.7 \pm 3 \%$ for the control NWs with a native oxide layer.

The magnetization curves of both samples of NWs with different oxidation level are shown in Fig. 1d. From these, the values of the saturation magnetization $\left(\mathrm{M}_{\mathrm{S}}\right)$ are 108 $\mathrm{Am}^{2} / \mathrm{kg}$ of Fe for the NWs with a native oxide layer and $65 \mathrm{Am}^{2} / \mathrm{kg}$ of Fe for the oxidized sample. The $\mathrm{M}_{\mathrm{S}}$ of the 


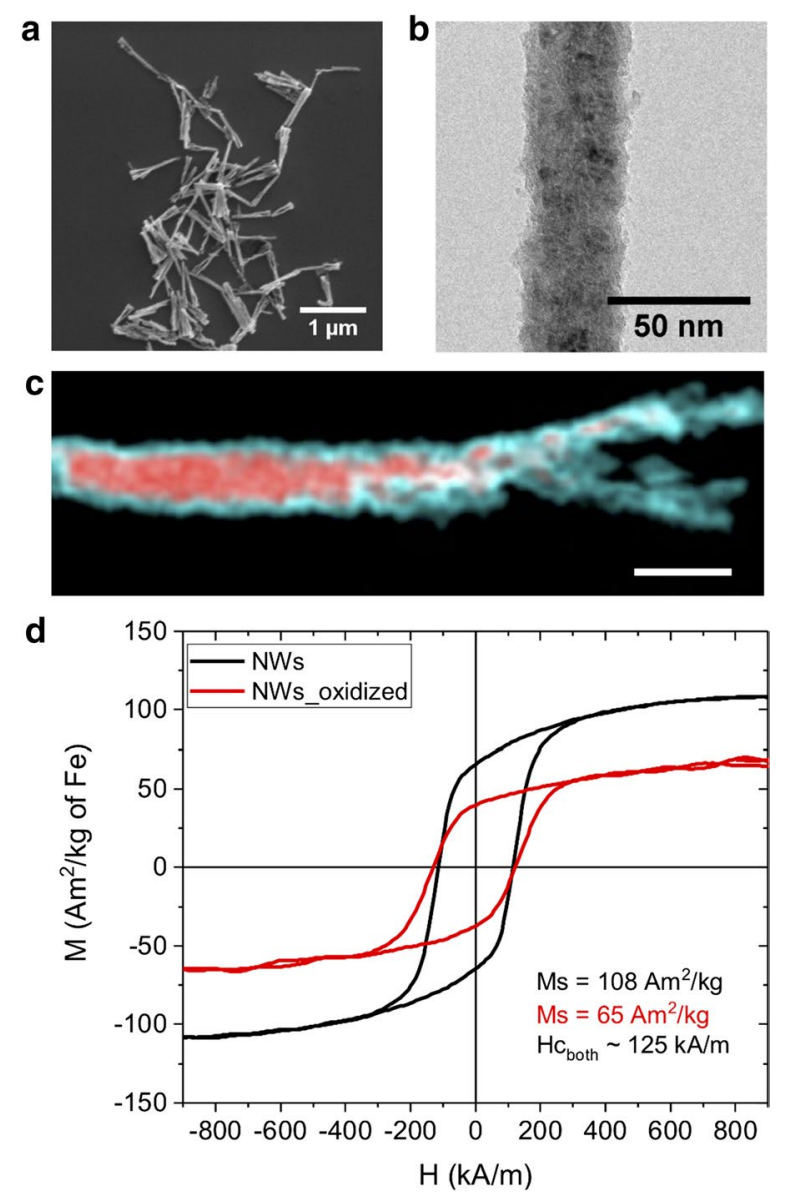

Fig. 1 Characterization of Fe-based NWs. a SEM image of NWs. b TEM image of NWs. c EELS mapping of a single NW. STEM image with superimposed Fe (red) and oxygen (blue) color mix map of NWs with native oxidation layer. The scale bar corresponds to $50 \mathrm{~nm}$. d Magnetization curves of Fe-based NWs with native oxide layer (black curve) and oxidized NWs (red curve) (Magnetization M is presented as $\mathrm{Am}^{2} / \mathrm{kg}$ of $\mathrm{Fe}, \mathrm{M}_{\mathrm{S}}$ is the saturation magnetization and $\mathrm{H}_{\mathrm{C}}$ the coercive field, $n=3$ )

non-oxidized NWs is higher than the $\mathrm{M}_{\mathrm{S}}$ reported for $\mathrm{Fe}_{2} \mathrm{O}_{3}$ and $\mathrm{Fe}_{3} \mathrm{O}_{4}$-based NPs [44-46], which increases the performance for $\mathrm{T}_{2}$ contrast [24], due to a more efficient induction of field inhomogeneity and a larger area of influence [21]. Yet, the measured $M_{S}$ values of both NW samples are lower than previously reported ones for longer Fe-based NWs inside of the alumina template (143 $\mathrm{Am}^{2} / \mathrm{kg}$ of $\mathrm{Fe}$ ) [47], and below the $\mathrm{M}_{\mathrm{S}}$ of bulk Fe at room temperature $\left(218 \mathrm{Am}^{2} / \mathrm{kg}\right)[48]$.

The NWs_oxidized showed approximately $40 \%$ reduction in the $\mathrm{M}_{\mathrm{S}}$ compared to NWs with native oxide layer, which is directly related to the increase in the thickness of the $\mathrm{Fe}_{\mathrm{x}} \mathrm{O}_{\mathrm{y}}$ shell in the oxidized sample [37]. It could also be attributed to corrosion (Fe ions lost in the hydrogen peroxide oxidation step) [49]. If assuming a linear relationship between the oxide shell volume and the $M_{S}$ reduction, it is easy to show that this $40 \%$ reduction in $\mathrm{M}_{\mathrm{S}}$ corresponds to an increase of shell thickness of around $4 \mathrm{~nm}$ in each NW. The coercive field was $\sim 125$ $\mathrm{kA} / \mathrm{m}$ for both formulations since the NWs take random orientations, compared to NWs inside a template.

In this study, NWs with a native oxide layer and NWs_oxidized were coated with (3-aminopropyl) triethoxysilane, APTES [50], (APTES-NWs and APTES-NWs oxidized, respectively) and NWs with native oxide layer were coated with bovine serum albumin, BSA, (BSANWs) as previously reported [51, 52]. The presence of both coating agents around the Fe-based NWs has been previously confirmed [38, 40,52], and has been shown to improve the biocompatibility and colloidal properties of the NWS with a reduction of agglomeration and enhancement of dispersion [40,43]. Such improvement can be attributed to electrostatic interactions supported by a zeta potential of $-58 \mathrm{mV}$ [43] and $-17.4 \mathrm{mV}$ [52] for the BSA-NWs and APTES-NWs, respectively. Furthermore, the presence of free chemical groups of both, BSA and APTES enables further functionalization of the NWs [40, $43,51,53]$.

\section{Relaxivity measurements}

The longitudinal $\left(r_{1}\right)$ and transversal $\left(r_{2}\right)$ relaxivities, as well as $r_{2} / r_{1}$ ratios, for different formulations of NWs were calculated from the relaxation times measured on an MR relaxometer at 1.5 T (Additional file 1: Figure S2, Table S2) in a preliminary characterization. Linear fitting of the relaxation rates $\left(R_{1}=1 / T_{1}\right.$, Additional file 1: Figure S2A and $R_{2}=1 / T_{2}$, Additional file 1: Figure S2B), as a function of Fe concentration, was performed using:

$$
R_{1,2}\left(s^{-1}\right)=R_{10,20}+r_{1,2}[C A]
$$

where $R_{10,20}$ are the relaxation rates of the solvent, $R_{1,2}$ the relaxation rates of NW solutions and $[\mathrm{CA}]$ the concentration of CA. Considering the elevated $r_{2}$ values and $\mathrm{r}_{2} / \mathrm{r}_{1}$ ratios obtained for all Fe-based NW formulations, and their practically negligible effect on $\mathrm{T}_{1}$, these materials can be considered as competitive $\mathrm{T}_{2}$ CAs (Additional file 1: Table S2) [7]. Moreover, the performance of Fe-based NWs for $\mathrm{T}_{2}$ contrast $\left(\mathrm{r}_{2}\right.$ ranging from 35 to $70 \mathrm{~s}^{-1} \mathrm{M}^{-1}$ ) is close to commercial $\mathrm{Fe}_{\mathrm{x}} \mathrm{O}_{\mathrm{y}}$-based CAs such as Endorem ${ }^{\mathrm{TM}}\left(\mathrm{r}_{2} \sim 41 \mathrm{~s}^{-1} \mathrm{mM}^{-1}\right)$ and Resovist $\left(\mathrm{r}_{2} \sim 61 \mathrm{~s}^{-1} \mathrm{mM}^{-1}\right)$ at $1.5 \mathrm{~T}$ [54].

Initial exploration of $r_{2}$ relaxivities of selected formulations of Fe-based NWs at preclinically $(7 \mathrm{~T})$ relevant magnetic field (Table 1), showed that $r_{2}$ values varied with time. Therefore, a set of experiments was performed measuring $\mathrm{r}_{2}$ for $160 \mathrm{~min}$, with a lapse of $20 \mathrm{~min}$ between 
Table 1 Transversal $\left(r_{2}\right)$ relaxivity values and relaxivity half time decay of different nanowire formulations at $7 \mathrm{~T}$

\begin{tabular}{lll}
\hline Formulation & $\mathbf{r}_{\mathbf{2}}\left(\mathbf{s}^{\mathbf{- 1}} \mathbf{m M}^{-\mathbf{1}}\right)$ & $\mathbf{t}_{\mathbf{1 / 2}}(\mathbf{m i n})$ \\
\hline NWs & 281 & 23.6 \\
APTES-NWs & 221 & 34.3 \\
NWs_oxidized & 176.8 & 31.7 \\
APTES-NWs_oxidized & 155 & 26.6 \\
BSA-NWs & 50.1 & 51.4 \\
\hline
\end{tabular}

each time point. The first experimental $r_{2}$ value was obtained at $\mathrm{t}=20 \mathrm{~min}$ (time required for securing the samples inside the scanner, tuning the system, and acquire the required MR images). An exponential decay of $r_{2}$ with time was observed, and the estimated $r_{2}$ values (Table 1 ) at time zero (beginning of the magnetic field exposition) for each sample were obtained after fitting the $r_{2}$ vs. time plots to a mono-exponential decay equation (Additional file 1: Figure S3A). A semilogarithmic representation of the $r_{2}$ values over time (Additional file 1: Figure S3B), as well as the half time signal decay $\left(t_{1 / 2}\right.$ in Table 1$)$ for each of the NW formulations, confirm the mono-exponential decay of the $r_{2}$. The Fe-based NWs showed an $r_{2}$ comparable to the one reported for the commercial formulation Feridex ${ }^{\circledR}$ at $7 \mathrm{~T}\left(166.71 \mathrm{~s}^{-1} \mathrm{mM}^{-1}\right)$ [55]. A reduction in $r_{2}$ values is observed, when comparing non-oxidized and oxidized NWs (NWs vs. NWs_oxidized (non-coated formulations) and APTES-NWs vs. APTES-NWs_oxidized (coated formulations)). This decrease in $\mathrm{r}_{2}$ of $\sim 40 \%$ and $\sim 30 \%$ for the non-coated and coated formulations, respectively, is related to the $40 \%$ decrease in the $M_{S}$, due to the oxidation of the NWs, which, in turn, reduces NW agglomeration. It has been reported that different factors, such as chemical composition, particle size and geometry, agglomeration, and polydispersity directly interfere with $r_{2}$ [53, 56-61]. In fact, low levels of aggregation may lead to an increase of relaxivity, as aggregated particles in solution induce larger alterations of the local magnetic field (inhomogeneities). On the other hand, larger levels of aggregation may lead to particle sedimentation; hence, the relaxivity of the bulk solution will be reduced (approaching the one of the solvent) [62]. The NWs $r_{2}$ was also affected by the addition of coating agents, where a slight decrease in the $r_{2}$ was found when comparing the NWs coated with APTES with the non-coated NWs (NWs vs. APTES-NWs and NWs_oxidized vs. APTESNWs_oxidized). This decrease is attributed to an increase in steric stability [64] and indicates that the coating of the NWs produces a reduction in agglomeration, which affects the $r_{2}$ values [52, 53]. Besides, since the NWs behave as single magnetic domain structures, the magnetic inhomogeneities affecting the relaxation time of

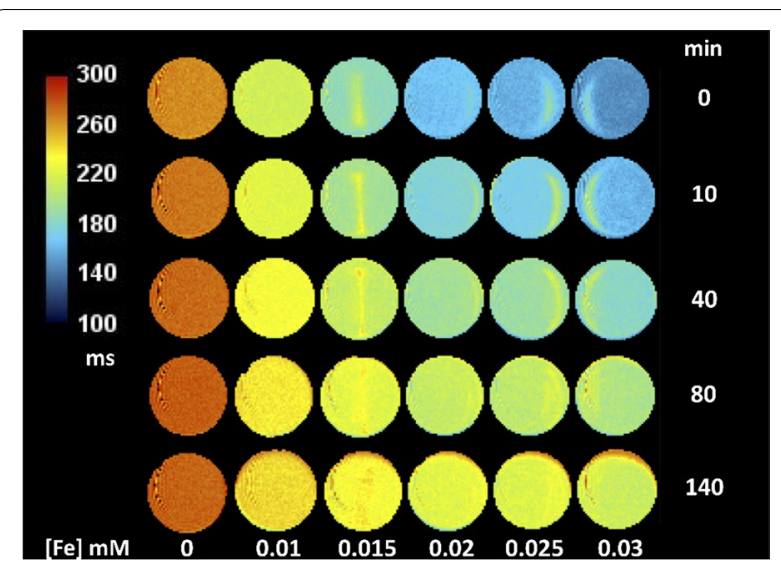

Fig. $2 T_{2}$ parametric maps (2D slices showing the section) of tubes filled with APTES-NWs aqueous solutions at five different concentrations ( $x$-axis), acquired at five selected time points ( $y$-axis) in a 7 T MRI. The first column at the left side contains HPLC grade water and was used as a control

the surrounding protons are generated only at the tips of the NWIs with no contribution of the NW body [6365]. The BSA-NWs present the lowest $r_{2}$, with a value at least three times lower than the other formulations. This reduction in the $r_{2}$ can be partially attributed to the large volume of BSA that not only prevents aggregation of particles by increasing the distance between them, by steric hindrance [51], but also increases the distance between the NWs and the surrounding protons, reducing the magnetic inhomogeneity $[66,67]$. Besides, BSA-NWs presented the largest half time of the $r_{2}$ signal, which is related to higher colloidal stability.

Although all samples were sonicated before the measurements, the magnetic field of the imaging system at $7 \mathrm{~T}$ enhanced the NW aggregation as exemplified in Additional file 1: Figure S4. There is an abrupt decrease (more than $70 \%$ ) of the $\mathrm{r}_{2}$ value (from 55.5 to $17.1 \mathrm{~s}^{-1} \mathrm{mM}^{-1}$ ) in the samples that remained inside the equipment throughout the measurement time (60 min, Additional file 1: Figure S4A) compared to the lower decrease of $r_{2}$ (from 67.4 to $51.7 \mathrm{~s}^{-1} \mathrm{mM}^{-1}, \sim 23 \%$ ) observed for the NWs that were placed in the MRI system only at the measurement time points ( $0 \mathrm{~min}$ and $60 \mathrm{~min}$, Additional file 1: Figure S4B). The NW aggregation and/or sedimentation enhancement by the magnetic field of the MRI equipment occurs through the NW alignment and attractive forces $[59,61]$. Several $\mathrm{Fe}_{\mathrm{x}} \mathrm{O}_{\mathrm{y}}$-based nanomaterials have been observed to cluster as a function of time in the presence of a magnetic field $[68,69]$.

The $\mathrm{T}_{2}$ parametric map of APTES-NWs (Fig. 2) shows a NW concentration dependence of the $R_{2}$. A sudden decrease in the $r_{2}$ during the first $40 \mathrm{~min}$ is observed similar to the decay observed in Additional file 1: Figure 
S4. Additionally, after $160 \mathrm{~min}$, the $\mathrm{r}_{2}$ of the most diluted NW solution tended towards the $r_{2}$ value of HPLC grade water, used as control. As explained above, this decay of $r_{2}$ values is attributed to aggregation and sedimentation of NWs in suspension, which is more pronounced in presence of high magnetic fields. Variations in the relaxation times, and therefore the colors, are visible in some of the tubes and can be explained by the inhomogeneous distribution of the NWs in suspension given by the aggregation and sedimentation.

\section{Magnetic resonance imaging of nanowires internalized in breast cancer cells}

Studies on the cellular uptake and degradation of NWs with similar dimensions as well as the cellular internalization and biocompatibility of Fe-based NWs (identical to the ones used in this study) coated with APTES and BSA in MDA-MB-231 cancer cells have been previously reported $[40,43,70,71]$. Cellular internalization of NWs is a continuous process that starts upon contact between NWs and cells [52], and takes place through the activation of the integrin-mediated phagocytosis pathway [26, 72]. Here, inductively coupled plasma mass spectrometry (ICP-MS) measurements were performed to quantify the NWs interacting with the cells. A total amount of $\sim 35 \mathrm{pg}$ of $\mathrm{Fe} /$ cell was found for cells incubated with APTESNWs and $117 \mathrm{pg} F$ Fe/cell for the cells incubated with BSA-NWs for $24 \mathrm{~h}$ without transfection agent. These values represent an internalization of $\sim 40 \%$ and $\sim 76 \%$ from the total amount of APTES-NWs and BSA-NWs added to the cells, respectively, corroborating our previous findings. It is worth mentioning that these values refer not only to internalized NWs, but also to NWs embedded in or adsorbed onto the extracellular structures surrounding the plasmatic membrane, and which can be present even after several washing steps.

In vitro studies of Fe NWs internalized in breast cancer cells were performed to evaluate their efficiency as $\mathrm{T}_{2}$ cell labeling CAs (Fig. 3). Serial dilutions from a suspension of MDA-MB-231 cells labeled with APTES-NW/s $(12 \mu \mathrm{g}$ of $\mathrm{Fe} / \mathrm{mL})$ or BSA-NWs $(20 \mu \mathrm{g}$ of $\mathrm{Fe} / \mathrm{mL})$ were sandwiched in an agar gel and a cell suspension of non-labeled cells was used as a negative control $(\mathrm{n}=3)$. 3D-Gradient Echo $\mathrm{T}_{2}{ }^{*}$ weighted MRI images were generated for each gel $24 \mathrm{~h}$ after implantation in a $7 \mathrm{~T}$ MRI equipment, from which a single $2 \mathrm{D}$ image was constructed by minimal intensity projection of all stacked slices that showed the presence of cells. The integrated $\mathrm{T}_{2}{ }^{*}$ signals of each of these $2 \mathrm{D}$ projections were measured for each dilution of cells labeled with NWs and control (non-labeled) cells and the signal intensity was normalized to the value observed for agars. Averaged $\mathrm{T}_{2}{ }^{*}$ weighted images of different concentrations of labelled cells in agar are
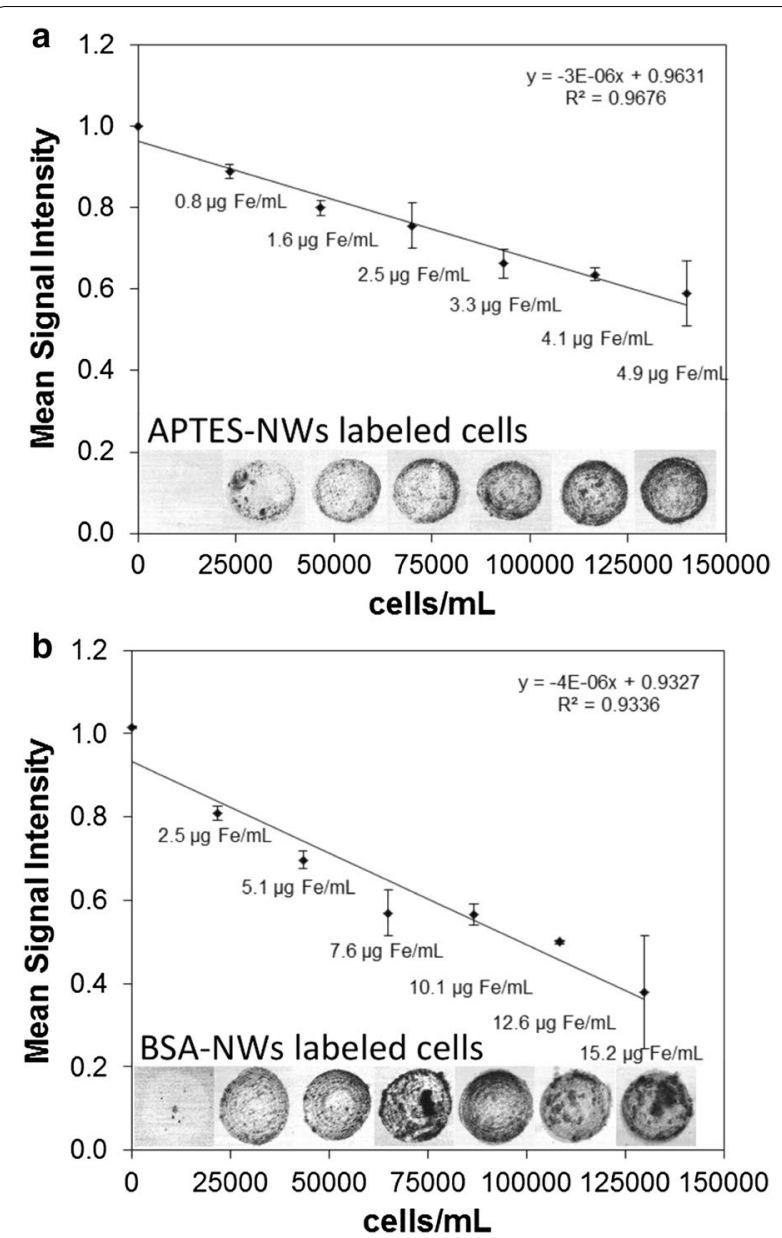

Fig. 3 Variation of mean signal intensity $( \pm S D, n=3)$ with the concentration of MDA-MB-231 cells labeled with APTES-NWs (a) or BSA-NWs (b). Averaged $T_{2}{ }^{*}$ weighted images (acquired at $7 \mathrm{~T}$ ) of cells are presented at the bottom of the plots, for each cell concentration

presented together with the mean $( \pm \mathrm{SD})$ signal intensity, for APTES-NWs (Fig. 3a) or BSA-NWs (Fig. 3b). In $\mathrm{T}_{2}{ }^{*}$ weighted images, signal intensity $(S)$ is exponentially dependent on the relaxation rate $\mathrm{R}_{2}{ }^{*}$ :

$$
S=S_{0} \exp \left(-T E R_{2}^{*}\right)
$$

where $S_{0}$ is the value of $\mathrm{S}$ extrapolated to a null echo time $\mathrm{TE}=0$, i.e. in absence of $\mathrm{T}_{2}{ }^{*}$ relaxation. Thus, according to Eqs. 1 and 2, $S$ is directly proportional to the concentration of $\mathrm{CA}$ ( $\mathrm{Fe}$ inside the cells), so the larger the number of labeled cells, the larger the $R_{2}{ }^{*}$ value (Eq. 1), and the lower the mean signal intensity (Eq. 2).

Overall, cell labeling with both formulations show a similar trend in the reduction of the mean signal intensity of MDA-MB-231 cells (Fig. 3). Although BSA-NWs showed an $r_{2}$ ca. 5 times lower than the APTES-NWs, a similar number of cells with similar mean signal 
intensities were observed when comparing wells enclosing cells with the same Fe concentration for both formulations. This can be partially explained by the higher concentration of the BSA-NWs added to the cells and the higher cellular internalization of this formulation. A minimum cell concentration of approx. 25 cells $/ \mu \mathrm{L}$ was detected using a NW concentration of $0.8 \mu \mathrm{g}$ of $\mathrm{Fe} / \mathrm{mL}$ and $2.5 \mu \mathrm{g}$ of $\mathrm{Fe} / \mathrm{mL}$ for the cells labeled with APTESNWs (Fig. 3a) and BSA-NWs (Fig. 3b), respectively. $\mathrm{T}_{2}{ }^{*}$ weighted images show a signal intensity distributed evenly throughout the whole well, indicating that labelled cells are distributed with minor aggregation. Hypointense regions at the edges of the wells given by cell accumulation were unavoidable, due to how the wells were produced in the gel. Micro air bubbles inside of the agar gel are seen as big black spots in $\mathrm{T}_{2}{ }^{*}$ weighted images (Fig. 3a, b) and could influence the signal intensity measured in each gel (false positives). This fact is reflected in the SD at each cell concentration. The resolution of MRI cell detection depends on many factors such as the $r_{2}$ value of the $\mathrm{CA}$, the amount of internalized nanomaterial per cell, the MRI protocol, scanner specifications, and has reached the point of single-cell detection using $\mathrm{Fe}_{\mathrm{x}} \mathrm{O}_{\mathrm{y}}$-based nanoparticle labels [73]. The limit of cell detection with the core-shell $\mathrm{Fe}-\mathrm{Fe}_{\mathrm{x}} \mathrm{O}_{\mathrm{y}} \mathrm{NWs}$ was not elucidated in our experimental setup. Nevertheless, the results show the efficiency and sensitivity of Fe-based NWs as $T_{2}$ CAs for cellular detection in systems simulating the tissue environment. The BSA-NWs were selected for further studies, due to their higher internalization compared to the APTES-NWs.

Finally, the sensitivity of MRI detection of Fe-based NWs-labeled cells was tested in vivo by injection of the BSA-NWs labeled cells after implantation in mice brains ( $\mathrm{n}=3$, Fig. 4). Circa 10 cells (Fig. 4a left, $3 \mu \mathrm{l}$ of a 3500 cells $/ \mathrm{ml}$ solution) and ca. 100 cells (Fig. 4a right, $3 \mu \mathrm{l}$ of a 35,000 cells $/ \mathrm{ml}$ solution) that were previously labeled with BSA-NWs were injected in the left and right hemisphere of a mouse brain, respectively, and immediately imaged by MRI at $11.7 \mathrm{~T}$. Cell deposits are visible along the channel opened by the injection needle (backflow of cells along the needle track is difficult to avoid), and some of the cells ended up in the ventricles as indicated by the hollow arrows in Fig. 4a. The presence of large blood vessels in the field of view (dashed arrows in Fig. 4a) highlights one of the main problems of the in vivo use of negative CAs, which is the lack of specificity between exogenous labeled cells and endogenous negative contrast (in this case lack of signal in vessels due to blood flow). Nevertheless, the labeling provided by BSA-NWs was so effective that the sensitivity of detection could be pushed to the limit of enabling the location of small clusters of labeled cells,
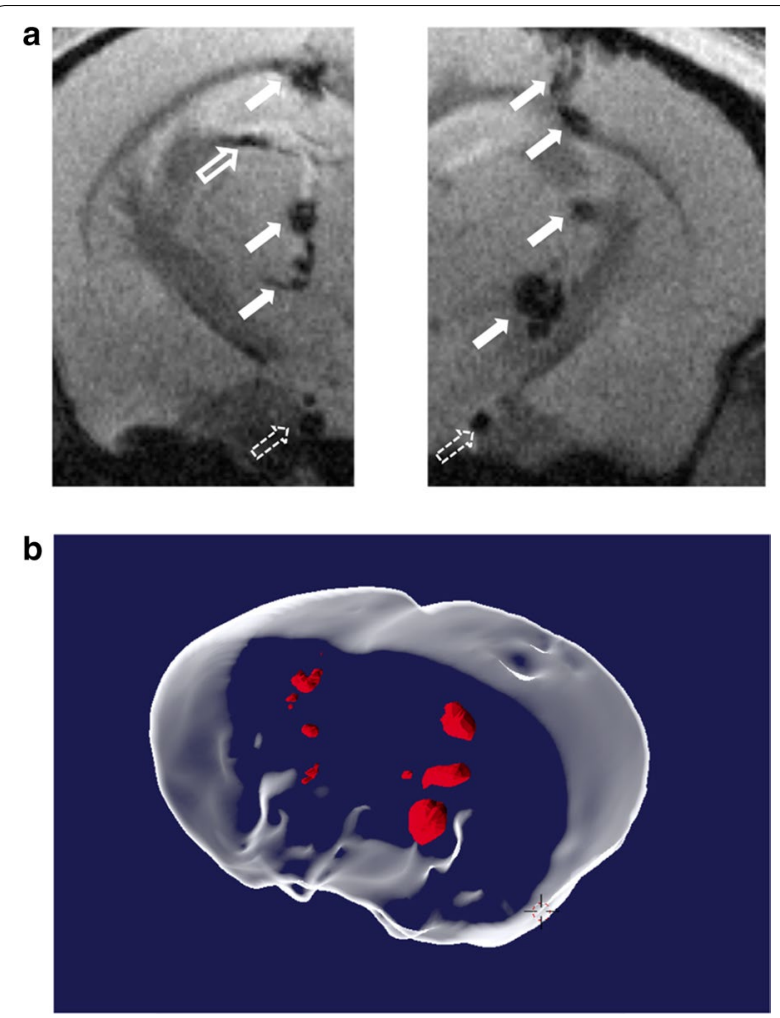

Fig. 4 Detection of MDA-MB-231 cells labeled with BSA-NWs implanted in brains of living mice at 11.7 T. a Axial MR images of the brain of a mouse immediately after implantation of MDA-MB-231 cells labeled with BSA-NWs. Circa 10 cells were implanted on the left hemisphere (left image), while circa 100 cells were implanted in the right hemisphere (right image). NW labeled cells are distributed along the track opened by the needle used for their implantation (solid arrows), and partially infiltrated in the brain ventricle (hollow arrow). Large blood vessels (dashed arrows) appear as false positives for cell deposits (lack of specificity is a known limitation for in vivo imaging of $\mathrm{T}_{2}$ CAs). $\mathbf{b}$ Surface rendered reconstruction of the $3 \mathrm{D}$ set of $\mathrm{T}_{2}{ }^{*}$ weighted images of the mice brain acquired after implantation of NW labeled cells. The signal produced by the labeled cells appears in red

as observed in Fig. 4a. A surface rendered reconstruction of the 3D set of all $\mathrm{T}_{2}{ }^{*}$ weighted images of the mice brain is shown in Fig. 4b, where the signal generated by the cells containing NWs appear in red color.

MR imaging following the implantation of labeled cells in alive mice confirmed that the NWs produce an intense $\mathrm{T}_{2}{ }^{*}$ contrast visible for several weeks (at least 6) after implantation (Additional file 1: Figure S5). High-resolution $\mathrm{T}_{2}{ }^{*}$ weighted $3 \mathrm{D}$ images were acquired immediately after injection and 10,20 and 40 days after implantation, showing the presence of NWs in a series of $2 \mathrm{D}$ image slice projections obtained from the $3 \mathrm{D}$ set. A detailed view of the cell location is presented in Fig. 5, where minimal intensity projections of all 2D slices with presence of NWs were constructed. 

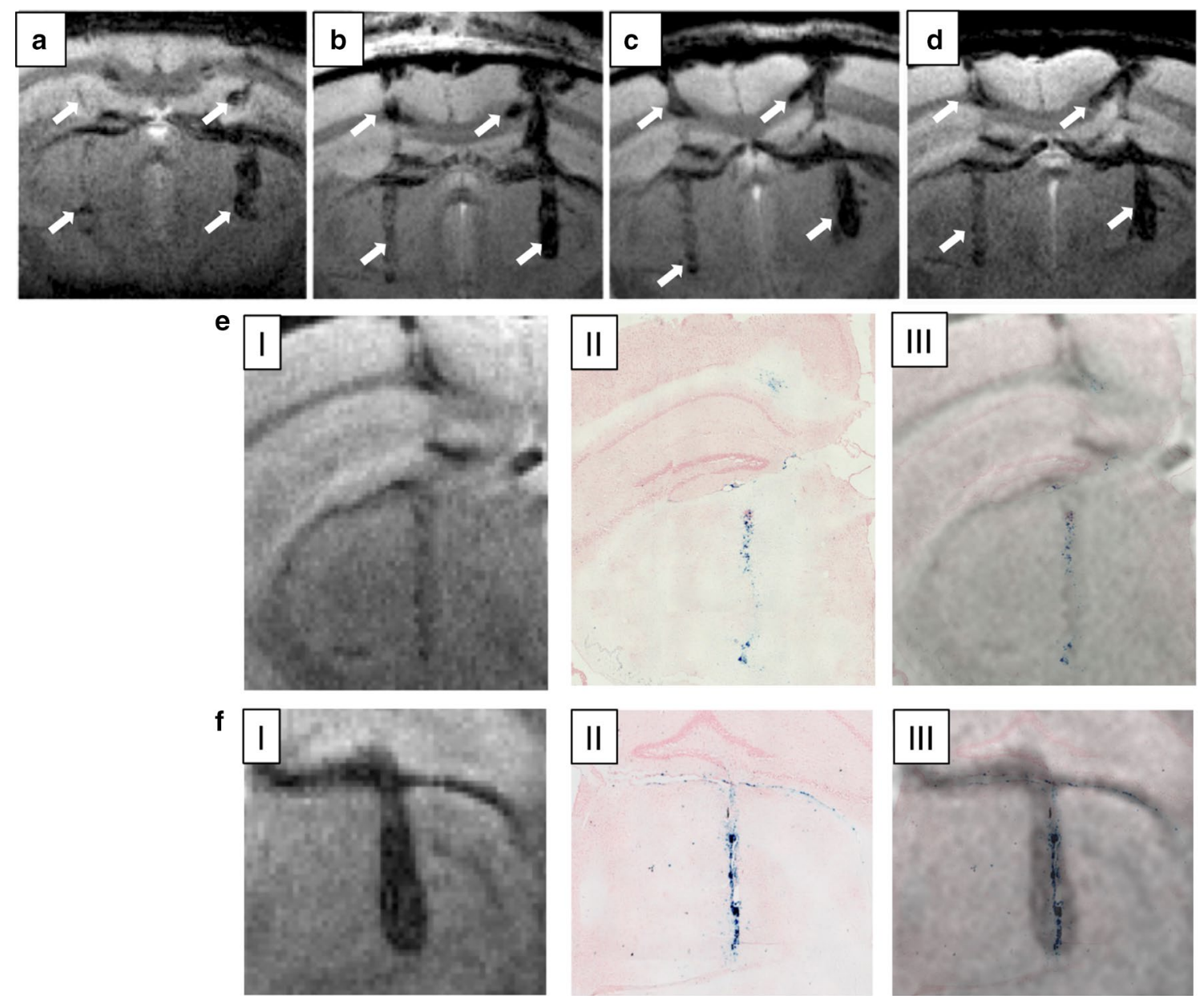

Fig. 5 Distribution of MDA-MB-231 cells labeled with BSA-NWs after implantation in mouse brain at 11.7T. Minimal intensity projections of all brain transverse 2D slices of the 3D image sets where BSA-NW labeled cells were present. Circa 10 cells were implanted on the left hemisphere (left side of the images), while circa 100 cells were implanted in the right hemisphere (right side of the images). Images were acquired immediately after implantation (a), and at days 10 (b), 20 (c), and 40 (d) post-implantation in living mouse. White arrows indicate the distribution of implanted cells along the injection needle tracks and into the corpus callosum. Correlation of mouse brain MRI images of implanted NW-labeled cells and optical images of histological slices of the same brain region stained with Perls' Prussian blue for Fe detection 40 days post-implantation. Magnification of the left (e) and right (f) hemispheres showing MRI images (I), optical microscopy images of histological preparations (II), and overlay of both imaging methods (III). Perls' Prussian blue stains NWs in blue due to the presence of $\mathrm{Fe}^{3+}$ in the oxide shell

Panels B-D in Fig. 5 shows that the labeled cells are distributed not only along the injection needle tracks but also traveled between injection sites along the corpus callosum. This could be potentially due to the activity of macrophages that engulfed injected cells, as part of the immune response to the implantation of exogenous cells in immune-competent mice rather than the active migration of the implanted cells. Our proof of principle in vivo studies do not provide information about the viability of the implanted cells and/or the integrity of the NWs throughout the weeks after the implantation. However, it has been reported that NWs with similar dimensions were observed inside of endosomes $24 \mathrm{~h}$ post-incubation with cells, and that a minimal fraction $(\sim 2 \%)$ of the NWs was dissolved intracellularly after $72 \mathrm{~h}$ due to the acidic environment of the lysosomal compartments in the cytoplasm [72]. Furthermore, large biodegradation of Fe nanoparticles was only observed after almost 1 month in a tissue environment and was partially determined by a decay on the $\mathrm{M}_{\mathrm{S}}$ value [74]. A comparison between the NW-labeled cells detected by MRI (in vivo) and optical microscope images (ex vivo) of mice brain slices stained with Pearls' Prussian blue for Fe detection, confirms the presence of $\mathrm{Fe}$ at the implantation site after 40 days and the correlation between NW labeling and the MRI $\mathrm{T}_{2}{ }^{*}$ contrast 
(Fig. 5e, f). Throughout the 40 days and with 5 imaging sessions of $3 \mathrm{~h}$ exposure to the MRI's magnetic field the labeled cells and NWs seem to be homogenously distributed, with no significant agglutination points.

The core-shell NWs have already been used for different therapeutic applications such as cancer cell killing through different modalities including $\mathrm{pH}$-triggered drug delivery, magneto-mechanic actuation [40], and more recently photothermal therapy, where the NWs showed an outstanding heating efficiency [43]. Functionalization with targeting agents allowed the selective interaction with leukemic cells [38], and these NWs show potential for hyperthermia treatment and magnetic guiding [75, 76]. The possibility of using the NWs as MRI contrast agents opens the door for theranostics in diseases such as cancer, where different strategies can be combined for targeting (magnetic guiding and targeting agents) and for treatment, while following the process in a non-invasive manner. Specifically, MRI cell tracking with NWs can be applied for cell therapy in diverse pathologies including degenerative disorders, where pluripotent cells labeled with NWs can be magnetically guided and concentrated into the target site and their differentiation induced by photothermal, magnetic or mechanical responses of the NWs, as suggested in different publications [77-80].

\section{Conclusions}

In this work, it is demonstrated the excellent performance of Fe-based NWs for $\mathrm{T}_{2}$ contrast in MRI detection of labeled cells. The capability of these $\mathrm{Fe}^{-\mathrm{Fe}_{\mathrm{x}} \mathrm{O}_{\mathrm{y}}}$ core-shell NWs with their high magnetization values to act as $\mathrm{T}_{2}\left(\mathrm{~T}_{2}{ }^{*}\right)$ MRI CAs, as well as the effects of different variables on the $T_{2}$ contrast such as level of oxidation of the NWs and surface coatings, were evaluated by measuring their $r_{2}$ values at a preclinical relevant field. It was found that the $r_{2}$ value of the NWs can be tailored by modifying the thickness of the oxide shell and by the addition of coating agents. $\mathrm{T}_{2}{ }^{*}$ weighted images of MDAMB-231 cells labeled with NWs embed in a tissue-like environment were produced testing two different NW formulations, whereby BSA coating not only enhanced dispersion and cellular internalization, but also showed a similar efficiency for MRI cell detection to the APTES coated NWs, despite having a smaller $r_{2}$ value. Therefore, a lower concentration of BSA coated NWs can be employed to efficiently label the cells reducing, in turn, the possibility of toxic effects. In vitro, labeling of cancer cells with NWs at a concentration of $0.8 \mu \mathrm{g}$ of $\mathrm{Fe} / \mathrm{mL}$ enabled the detection of $\sim 25$ cells $/ \mu \mathrm{L}$. In vivo studies showed that ca.10 NW-labeled cells could be located in the brain parenchyma of a mouse and were detectable for at least 40 days after implantation. The efficient and longitudinal cellular detection combined with the possibility of magnetic guidance of the NW labeled cells as well as triggering cellular responses opens the door to new horizons in cell therapy. These results together with the capacity of functionalization, magnetic responses, and the recently discovered qualities as a photothermal agent make the $\mathrm{Fe}_{-} \mathrm{Fe}_{\mathrm{x}} \mathrm{O}_{\mathrm{y}}$ core-shell NWs a promising theranostic platform.

\section{Methods}

The main aspects of the methods are mentioned in this section. For detailed explanations of some of the procedures, see Additional file 1.

\section{Chemical reagents}

Bovine serum albumin (BSA), 98\% (3-aminopropyl) triethoxysilane (APTES), and 0.25\% trypsin-EDTA solution were purchased from Sigma-Aldrich. 30\% hydrogen peroxide was purchased from Electron Microscopy Sciences, Pennsylvania, USA. HPLC grade water (Sigma Aldrich) was used in all experiments if not indicated otherwise.

\section{Cell culture}

The MDA-MB-231 cell line was purchased from American Type Culture Collections (Manassas, VA, USA). It was grown as a monolayer in Dulbecco's Modified Eagle's Medium (DMEM) supplemented with 10\% fetal bovine serum (FBS), $2 \mathrm{mM} \mathrm{L-glutamine,} 100$ units of penicillin/ $\mathrm{mL}$ and $100 \mu \mathrm{g} / \mathrm{mL}$ of streptomycin. All reagents were purchased from GIBCO. Cells were maintained in an incubator at $37{ }^{\circ} \mathrm{C}$ in a humidified atmosphere of $95 \%$ air and $5 \% \mathrm{CO}_{2}$.

\section{Preparation and characterization of nanowire formulations} $\mathrm{Fe}^{-} \mathrm{Fe}_{\mathrm{x}} \mathrm{O}_{\mathrm{y}}$ core-shell NWs were fabricated by chemical electrodeposition into nanoporous alumina membranes, as previously reported [27-29, 72]. The NWs' length of $\sim 700 \mathrm{~nm}$ was controlled by the deposition time (16 min). The NWs were released from the alumina template and collected with a magnetic rack (DynaMag ${ }^{\mathrm{TM}}-2$; Life Technologies, Carlsbad, CA, USA) and rinsed thoroughly 10 to 15 times with ethanol with sonication steps of $10 \mathrm{~s}$ in-between. Finally, the released NW's were suspended in $1 \mathrm{~mL}$ of absolute ethanol. Thereafter, the sample of NWs was suspended in an aqueous solution of hydrogen peroxide $15 \% \mathrm{v} / \mathrm{v}$ and left in a thermomixer (Thermomixer comfort, Eppendorf) at $400 \mathrm{rpm}$ and $40{ }^{\circ} \mathrm{C}$ for 3 weeks. The sample was then washed five times with absolute ethanol with sonication periods in between.

The morphology, length, and diameter of the NWs were investigated by SEM (Quanta 3D; FEI Company, Hillsboro, OR, USA) and TEM (Tecnai BioTWIN; FEI Company). Images were analyzed using the NIH software Image J and the NWs' length was determined out 
of a hundred NWs from different samples. The chemical composition, as well as the level of oxidation of the NWs, were evaluated by STEM and EELS by comparing the treated samples against control NWs that remained all the time in absolute ethanol at room temperature $(\mathrm{n}=3)$. To determine the oxidation level, the average relative concentrations of Fe and oxygen were measured in identical regions of different single NWs, and the resultant ratio was compared between the control and treated samples of NWs $(n=3)$. TEM studies in combination with EELS were performed using a Thermo Fisher (former FEI) Titan 80-300 TEM equipped with a Cs probe corrector and a Gatan Imaging Filter Quantum 966. The microscope was operated at $200 \mathrm{kV}$. The EELS maps were acquired in STEM mode as so-called spectrum imaging. The impact of increasing the oxide layer thickness on the magnetic properties of the NWs was evaluated by measuring the magnetic hysteresis loops with a LakeShore 7404 Vibrating Sample Magnetometer $(\mathrm{n}=3)$ and the measurements were carried out on dried samples of dispersed NWs.

NWs were coated with APTES or BSA as described previously [40]. Briefly, NWs with native oxide layer and oxidized NWs were coated separately with APTES by adding $0.0946 \mathrm{~g}$ of APTES per each 100-300 mg of Fe to the NWs suspended in ethanol with a final volume of $5 \mathrm{~mL}$ and sonicated for $1 \mathrm{~h}$. Since basic catalysis is required for the reaction, $200 \mu \mathrm{L}$ of miliQ water and 10 $\mu \mathrm{L}$ of sodium hydroxide $1 \mathrm{M}$ were added, followed by a second sonication period of $1 \mathrm{~h}$. Finally, the NWs were washed five times with $1 \mathrm{~mL}$ absolute ethanol and stored at room conditions in an Eppendorf tube. For BSA coating, NWs with native oxide layer were suspended in $10 \mathrm{mM}$ phosphate buffer $\mathrm{pH}$ 7.4 (PB), to a final volume of $2.5 \mathrm{~mL}$ in a glass vial and added with $0.8 \mathrm{mg}$ of BSA/ $\mathrm{mg}$ of Fe, followed by 1.5 of sonication. The BSA coated NWs were washed three times with phosphate buffer and stored at $4{ }^{\circ} \mathrm{C}$ in sterile conditions. All NW formulations were stored at room temperature and are stable for at least 12 months after the coating. The Fe concentration in each NW-formulation stock solution and in cell suspensions was quantified by triplicate using an ICP-MS (iCAP-Q instrument, Thermo Fisher Scientific).

\section{Transversal relaxivity and magnetic resonance imaging measurements}

Transversal relaxivity measurements and in vitro imaging experiments were performed in a $7 \mathrm{~T}$ horizontal bore Bruker Biospec 70/30 USR scanner (Bruker Biospin, Ettlingen, Germany) using a BGA12-S imaging gradient set of $440 \mathrm{mT} / \mathrm{m}$ and a $40 \mathrm{~mm}$ inner diameter transmit/ receive volumetric coil. A set of 5 solutions of each NWs formulation with $\mathrm{Fe}$ concentrations ranging from 0.01 to
$0.03 \mathrm{mM}$ were measured at $37^{\circ} \mathrm{C}$ using a heated water blanket for temperature control. A tube with HPLC grade water was used as a control sample in all measurements. All samples were sonicated individually for $20 \mathrm{~s}$ before introducing them in the MRI equipment to ensure proper dispersion of the NWs. $\mathrm{T}_{2}$ relaxation time maps were acquired using a Multi-Slice Multi-Echo sequence with the following parameters: repetition time $(\mathrm{RT})=1500 \mathrm{~ms}$, echo time $(\mathrm{TE})=20 \mathrm{~ms}$, echo train of 24 equally spaced $\mathrm{TE}$ ( 20 to $480 \mathrm{~ms}, \Delta \mathrm{TE}=20 \mathrm{~ms}$ ), field of view $(\mathrm{FOV})=25.6 \mathrm{~mm} \times 12.8 \mathrm{~mm}$, image matrix $=256 \times 128$ points, one slice of $5 \mathrm{~mm}$ thickness and 2 averages. $T_{2}$ relaxation times of each sample were measured at fixed intervals of ca. $20 \mathrm{~min}$ throughout $160 \mathrm{~min} . \mathrm{R}_{2}$ relaxation rates were obtained as the reciprocal of $T_{2}$ relaxation times (obtained by fitting MR signal decay with echo time to a mono-exponential function) and the corresponding $r_{2}$ values were obtained using Eq. $1 . T_{2}$ parametric maps were generated for each of the NW samples and were calculated by fitting pixel intensities of the multi-echo images to a mono-exponential decay on a pixel by pixel basis.

The capacity of NWs to perform as CA for cell tracking was assessed by labeling of breast cancer cells and studying them with MRI when placed in vitro and in vivo. Cell suspensions with a concentration of $\sim 140,000$ cells $/ \mathrm{mL}$ were prepared from MDA-MB-231 cells labeled with APTES-NWs $(12 \mu \mathrm{g}$ of $\mathrm{Fe} / \mathrm{mL})$ and BSA-NWs $(20 \mu \mathrm{g}$ of $\mathrm{Fe} / \mathrm{mL}$ ). Five serial dilutions of the cells treated with each NW formulation were made (4200 to 700 cells / $\mathrm{mL})$. Likewise, 3 dilutions of the non-treated cells were made with a concentration of 4200 to 1400 cells $/ \mathrm{mL}$ ). $30 \mu \mathrm{L}$ of each dilution was applied to the wells of each one of the three agar gels previously prepared, which thereafter was left for $2 \mathrm{~h}$ at room temperature, enabling adsorption of the cells on the surface of the bottom of the wells. Subsequently, another agarose solution of $0.9 \%$ was prepared, left to reach just above physiological temperature and added to the three gels for filling the wells, therefore trapping the attached cells. Finally, gels were covered with Parafilm and left at $4{ }^{\circ} \mathrm{C}$ until imaging. For MRI acquisition, a Fast Low Angle Shot sequence was chosen to image 25 slices of $0.2 \mathrm{~mm}$ thickness. The FOV was $36 \times 36 \mathrm{~mm}^{2}$, acquired with a matrix of $512 \times 512$ points, resulting in an in-plane resolution of $70 \times 70 \mu \mathrm{m}^{2}$. For imaging, the following parameters were used: $\mathrm{TR}=500 \mathrm{~ms}, \mathrm{TE}=7.3 \mathrm{~ms}$, and 20 averages. For the quantitative analysis, all the slices containing cells were used to calculate the minimal intensity projection taking into account that transfected cells produce a dark contrast on MR images, which were normalized by subtracting the agarose gel background signal. Finally, the integrated signal intensity was calculated for each sample from the 
minimal intensity projection image, and its dependence with the volume of labeled cells was obtained. Signal intensity was normalized to the value observed for agar to correct for factors such as distance and orientation of sample to the MR coil, magnetic field shimming, receiver gain of the system and other parameters that can vary from one experiment to the next.

In vivo imaging experiments were performed in a 11.7 T horizontal bore Bruker Biospec 117/16 USR scanner (Bruker Biospin, Ettlingen, Germany) using a BGA9$\mathrm{S}$ imaging gradient set of $750 \mathrm{mT} / \mathrm{m}$, and a $72 \mathrm{~mm}$ inner diameter transmit volumetric coil and actively decoupled mouse head surface coil for detection (both from Bruker Biospin). All animal experiments were approved by the local IACUC and local authorities and under the European Union Directive 2010/63/EU on the protection of animals used for scientific purposes. A total of 3 mice (c57bl/6, male, $30 \mathrm{~g}$ ) were used in the study. Briefly, after induction of anesthesia with isoflurane animals were positioned in a stereotaxic frame, the head was shaved, and an incision on the skin was performed along the brain midline exposing the skull of the animal. Two small holes were buried (one per hemisphere) in the bone using a dentistry drill. The needle of a Hamilton syringe of $10 \mu \mathrm{l}$ containing the BSA-NWs-labeled cells solution, attached to the stereotaxic frame, was slowly introduced through each of the holes to a depth of $3.5 \mathrm{~mm}$ and raised $0.5 \mathrm{~mm}$ afterward (leaving a small reservoir to deposit the cells). A volume of $3 \mu \mathrm{l}$ of BSA-NWs-labeled cell solutions with the concentration of 3500 cells $/ \mathrm{ml}$ was injected in the left hemisphere, and 35,000 cells $/ \mathrm{ml}$ was injected in the right hemisphere resulting in approximately 10 cells and 100 cells on the left and right side, respectively. The cells were deposited during $5 \mathrm{~min}$ in the brain of the animal leaving the needle in site for another five minutes after finishing the injection to minimized backflow of cells through the needle track. Finally, acrylic glue was used to close the bone holes, and animals were sutured and transferred to the MRI where images were acquired under isoflurane anesthesia. $\mathrm{T}_{2}{ }^{*}$-weighted MRI images were acquired using the following imaging parameters: 3D-Multi-Gradient-Echo sequence, $\mathrm{TE}=4.35, \quad 10.6$, and $16.8 \mathrm{~ms}, \mathrm{TR}=80 \mathrm{~ms}$, flip angle $=15,6$ averages, FOV $=12.8 \times 9.6 \times 6.4 \mathrm{~mm}(3 \times$ FOV saturation bands $)$, image matrix $=256 \times 192 \times 32$ points (giving a spatial resolution of $50 \times 50 \times 200 \mu \mathrm{m}$ ) and effective bandwidth of $50 \mathrm{kHz}$. Images were acquired directly after implantation of cells and repeated after 10, 20, and 40 days.

\section{Histology}

After the last MRI session, animals were euthanized and perfused with $20 \mathrm{ml}$ of saline solution followed by $20 \mathrm{ml}$ of paraformaldehyde $4 \%$. Mice brains were extracted, rinsed with saline solution, and left in $4 \%$ paraformaldehyde overnight at $4{ }^{\circ} \mathrm{C}$. The brains were then placed into $50 \mathrm{ml}$ falcon tubes containing sucrose solution $20 \%$ and kept at $4{ }^{\circ} \mathrm{C}$ until they sunk to the bottom of the falcon. Finally, the brains were deeply frozen in methylbutane, cooled by dried ice, and cut in slices of $8 \mu \mathrm{m}$ using a cryostat Leica CM3050S. Tissues were placed in glass slides and dried in a stove for $1 \mathrm{~h}$. For Perls' Prussian blue staining, slides were first immersed in distilled water for $30 \mathrm{~s}$, then in a $6 \%$ Perls' solution A (Potassium ferrocyanide trihydrate) plus Perls' solution $\mathrm{B}(\mathrm{HCl})$ for $1 \mathrm{~h}$. Slides were immersed in Fast Red for 2 min, washed with water and dehydrated with an ascending gradient of ethanolwater mixtures (ethanol 50\%, 75\%, 96\%, 3-4 min in each mixture). Finally, slides were immersed into xylene for 3 min and covered with a DPX mount for histology.

\section{Supplementary information}

Supplementary information accompanies this paper at https://doi. org/10.1186/s12951-020-00597-3.

\begin{abstract}
Additional file 1. Supplementary figures describe the schematic of Fe-based NWs oxidation and its evaluation, the variation of the relaxation rates as a function of the Fe-based NW concentration at $1.5 \mathrm{~T}$ for different NW formulations, the decay of the $r_{2}$ values obtained at $7 \mathrm{~T}$ across the time for different NW formulations, the influence of the NWs' magnetization in the $r_{2}$ decay across time, and four axial consecutive slices of $200 \mu \mathrm{m}$ of thickness across the brain of a mouse implanted with BSA-NWs labeled cells. Supplementary tables describe the determination of the oxidation level of Fe NWs through elemental quantification, and the longitudinal $\left(r_{1}\right)$ transversal $\left(r_{2}\right)$ relaxivities and $r_{2} / r_{1}$ ratio of different nanowire formulations at $1.5 \mathrm{~T}$. Supplementary methods describe the synthesis of nanowires, the magnetic characterization of nanowires, the quantification of iron nanowires, the relaxivity measurements at $1.5 \mathrm{~T}$, the magnetization effect of iron nanowires at the $7 \mathrm{~T}$, the preparation of cell suspensions for in vitro MRI detection and the preparation of agar gels for MRI imaging phantom studies.
\end{abstract}

\section{Abbreviations}

NW(s): Nanowire(s); BSA: Bovine serum albumin; APTES: (3-aminopropyl)triethoxysilane; CA: Contrast agent; PBS: Phosphate buffer saline; Fe: Iron; $\mathrm{Fe}_{\mathrm{x}} \mathrm{O}_{\mathrm{y}}$ : Iron oxide; FOV: Field of view; ICP-MS: Inductively coupled plasma mass spectrometry; MRI: Magnetic resonance imaging; $T_{1}$ : Longitudinal relaxation time; $\mathrm{T}_{2}$ : Transversal relaxation time; TE: Time to echo; TEM: Transmission electron microscopy; TR: Time to repetition; SEM: Scanning electron microscopy; EELS: Electron energy loss spectroscopy; STEM: Scanning transmission electron microscopy; $M_{5}$ : Saturation magnetization; $H_{C}$ : Coercivity; $r_{1}$ : Longitudinal relaxivity; $r_{2}$ : Transversal relaxivity; $R_{1}$ : Longitudinal relaxation rate; $R_{2}$ : Transversal relaxation rate.

\section{Acknowledgements}

We thank Sergei Lopatin (Imaging and Characterization Core Lab at KAUST).

\section{Authors' contributions}

JK, ALC and PR-C conceived work and designed the experiments. JK, ALC, PRC, TR, and JSM supervised the work. JAM and AIM synthesized and characterized the iron nanowires. AIM-B, AA, SP-G, LC and PR-C performed the MRI experiments. All authors discussed the results and contributed to writing the manuscript. All authors read and approved the final manuscript.

\section{Funding}

Research reported in this publication was supported by the King Abdullah University of Science and Technology (KAUST), The Spanish State Research 
Agency (RETOS Program Grant No. BIO2016-77367-R and SAF2017-87670-R, Maria de Maeztu Units of Excellence Program Grant No. MDM-2017-0720), and the Basque Government (Elkartek KK-2017/00008).

\section{Availability of data and materials}

All data generated or analyzed during this study are included in this published article and its supplementary information files.

\section{Ethics approval and consent to participate}

All animal experiments were approved by the local IACUC and local authorities and under the European Union Directive 2010/63/EU on the protection of animals used for scientific purposes.

\section{Consent for publication}

Not applicable.

\section{Competing interests}

The authors declare that they have no competing interests.

\begin{abstract}
Author details
${ }^{1}$ Division of Biological and Environmental Sciences and Engineering, King Abdullah University of Science and Technology, Thuwal, Jeddah 23955-6900, Saudi Arabia. ${ }^{2}$ Center for Cooperative Research in Biomaterials (CIC biomaGUNE), Basque Research and Technology Alliance (BRTA), Paseo de Miramon 182, 20014 Donostia San Sebastián, Spain. ${ }^{3}$ Division of Computer, Electrical and Mathematical Sciences and Engineering, King Abdullah University of Science and Technology, Thuwal, Jeddah 23955-6900, Saudi Arabia. ${ }^{4}$ Ikerbasque, Basque Foundation for Science, Ma Díaz de Haro 3, 48013 Bilbao, Spain. ${ }^{5}$ IMDEA Nanociencia and Nanobiotechnology Unit Associated to Centro Nacional de Biotecnología (CNB-CSIC), Campus Universitario de Cantoblanco, 28049 Madrid, Spain.
\end{abstract}

Received: 16 December 2019 Accepted: 27 February 2020 Published online: 12 March 2020

\section{References}

1. Hilger I, Kaiser WA. Iron oxide-based nanostructures for MRI and magnetic hyperthermia. Nanomedicine. 2012;7(9):1443-599.

2. Krishnan KM. Biomedical nanomagnetics: a spin through possibilities in imaging, diagnostics, and therapy. IEEE Trans Magn. 2010;46(7):2523-58.

3. Golovin Yl, Gribanovsky SL, Golovin DY, Klyachko NL, Majouga AG, Master AM, et al. Towards nanomedicines of the future: Remote magnetomechanical actuation of nanomedicines by alternating magnetic fields. J Control Rel. 2015;219:43-60.

4. Espinosa A, Di Corato R, Kolosnjaj-Tabi J, Flaud P, Pellegrino T, Wilhelm C. Duality of iron oxide nanoparticles in cancer therapy: amplification of heating efficiency by magnetic hyperthermia and photothermal bimodal treatment. ACS Nano. 2016;10(2):2436-46.

5. Jacobs MA, Ibrahim TS, Ouwerkerk R. MR Imaging: brief overview and emerging applications. RadioGraphics. 2007;27(4):1213-29.

6. Villaraza AJ, Bumb A, Brechbiel MW. Macromolecules, dendrimers, and nanomaterials in magnetic resonance imaging: the interplay between size, function, and pharmacokinetics. Chem Rev. 2010;110(5):2921-59.

7. Na HB, Song IC, Hyeon T. Inorganic nanoparticles for mri contrast agents. Adv Mater. 2009;21(21):2133-48.

8. Caravan P, Ellison JJ, McMurry TJ, Lauffer RB. Gadolinium(III) chelates as MRI contrast agents: structure, dynamics, and applications. Chem Rev. 1999;99(9):2293-352.

9. Dias MHM, Lauterbur PC. Ferromagnetic particles as contrast agents for magnetic resonance imaging of liver and spleen. Magn Reson Med. 1986;3(2):328-30.

10. Semelka RC, Helmberger TKG. Contrast agents for MR imaging of the liver. Radiology. 2001;218(1):27-38.

11. Hamm B, Staks T, Taupitz M, Maibauer R, Speidel A, Huppertz A, et al. Contrast-enhanced MR imaging of liver and spleen: first experience in humans with a new superparamagnetic iron oxide. J Magn Reson Imag. 1994;4(5):659-68.

12. Ferrucci JT, Stark DD. Iron oxide-enhanced MR imaging of the liver and spleen: review of the first 5 years. Am J Roentgenol. 1990;155(5):943-50.
13. Brisset J-C, Sigovan M, Chauveau F, Riou A, Devillard E, Desestret V, et al. Quantification of iron-labeled cells with positive contrast in mouse brains. Mol Imag Biol. 2011;13(4):672-8.

14. Okuhata Y. Delivery of diagnostic agents for magnetic resonance imaging. Adv Drug Deliv Rev. 1999;37(1):121-37.

15. Hendrick RE, Mark HE. Basic physics of MR contrast agents and maximization of image contrast. J Magn Reson Imag. 1993;3(1):137-48.

16. Lee N, Hyeon T. Designed synthesis of uniformly sized iron oxide nanoparticles for efficient magnetic resonance imaging contrast agents. Chem Soc Rev. 2012;41(7):2575-89.

17. Wang Y-XJ. Current status of superparamagnetic iron oxide contrast agents for liver magnetic resonance imaging. World J Gastroenterol. 2015;21(47):13400-2.

18. Reimer P, Balzer T. Ferucarbotran (Resovist): a new clinically approved RESspecific contrast agent for contrast-enhanced MRI of the liver: properties, clinical development, and applications. Eur Radiol. 2003;13(6):1266-76.

19. McCullough BJ, Kolokythas O, Maki JH, Green DE. Ferumoxytol in clinical practice: Implications for MRI. J Magn Reson Imag. 2013;37(6):1476-9.

20. Hoehn M, Wiedermann D, Justicia C, Ramos-Cabrer P, Kruttwig K, Farr T, et al. Cell tracking using magnetic resonance imaging. J Physiol. 2007;584(Pt 1):25-30.

21. Zhao Z, Zhou Z, Bao J, Wang Z, Hu J, Chi X, et al. Octapod iron oxide nanoparticles as high-performance $T 2$ contrast agents for magnetic resonance imaging. Nat Commun. 2013;4:2266.

22. Lassenberger A, Scheberl A, Stadlbauer A, Stiglbauer A, Helbich T, Reimhult E. Individually stabilized, superparamagnetic nanoparticles with controlled shell and size leading to exceptional stealth properties and high relaxivities. ACS Appl Mater Inter. 2017;9(4):3343-53.

23. Felfoul O, Becker AT, Fagogenis G, Dupont PE. Simultaneous steering and imaging of magnetic particles using MRI toward delivery of therapeutics. Sci Rep. 2016:6:33567.

24. Koenig SH, Kellar KE. Theory of $1 / \mathrm{T} 1$ and $1 / \mathrm{T} 2 \mathrm{NMRD}$ profiles of solutions of magnetic nanoparticles. Magn Reson Med. 1995;34(2):227-33.

25. Hultgren A, Tanase M, Chen CS, Meyer GJ, Reich DH. Cell manipulation using magnetic nanowires. J Appl Phys. 2003;93(10):7554-6.

26. Hultgren A, Tanase M, Felton EJ, Bhadriraju K, Salem AK, Chen CS, et al. Optimization of yield in magnetic cell separations using nickel nanowires of different lengths. Biotechnol Prog. 2005;21(2):509-15.

27. Masuda H, Fukuda K. Ordered metal nanohole arrays made by a 2-step replication of honeycomb structures of anodic alumina. Science. 1995;268(5216):1466-8.

28. Nielsch K, Muller F, Li AP, Gosele U. Uniform nickel deposition into ordered alumina pores by pulsed electrodeposition. Adv Mater. 2000;12(8):582-6.

29. Pirota KR, Navas D, Hernandez-Velez M, Nielsch K, Vazquez M. Novel magnetic materials prepared by electrodeposition techniques: arrays of nanowires and multi-layered microwires. J Alloys Compd. 2004;369(1-2):18-26.

30. Shore D, Pailloux SL, Zhang J, Gage T, Flannigan DJ, Garwood M, et al. Electrodeposited Fe and Fe-Au nanowires as MRI contrast agents. Chem Commun. 2016;52(85):12634-7.

31. Banobre-Lopez M, Bran C, Rodriguez-Abreu C, Gallo J, Vazquez M, Rivas J. A colloidally stable water dispersion of Ni nanowires as an efficient T2-MRI contrast agent. J Mater Chem B. 2017;5(18):3338-47.

32. Kasprzak KS, Sunderman FW, Salnikow K. Nickel carcinogenesis. Mutat Res. 2003;533(1-2):67-97.

33. Bulte JWM, Douglas T, Witwer B, Zhang S-C, Strable E, Lewis BK, et al. Magnetodendrimers allow endosomal magnetic labeling and in vivo tracking of stem cells. Nat Biotechnol. 2001;19:1141.

34. Bulte JWM, Duncan ID, Frank JA. In vivo magnetic resonance tracking of magnetically labeled cells after transplantation. J Cereb Blood Flow Metab. 2002;22(8):899-907.

35. Hoehn M, Küstermann E, Blunk J, Wiedermann D, Trapp T, Wecker S, et al. Monitoring of implanted stem cell migration in vivo: a highly resolved in vivo magnetic resonance imaging investigation of experimental stroke in rat. Proc Natl Acad Sci. 2002;99(25):16267-722.

36. Bulte JWM, Kraitchman DL. Iron oxide MR contrast agents for molecular and cellular imaging. NMR Biomed. 2004;17(7):484-99.

37. Ivanov YP, Alfadhel A, Alnassar M, Perez JE, Vazquez M, Chuvilin A, et al. Tunable magnetic nanowires for biomedical and harsh environment applications. Sci Rep. 2016;6:24189. 
38. Alsharif NA, Martinez-Banderas A, Merzaban J, Ravasi T, Kosel J. Biofunctionalizing magnetic nanowires toward targeting and killing leukemia cancer cells. IEEE Trans Magn. 2019;55(2):1-5.

39. Meng-Meng S, Wen-Jing S, Hong B, Jun W, Wei-Lin W, Jun S, et al. Cytotoxicity and cellular uptake of iron nanowires. Biomaterials. 2010;31(7):1509-17.

40. Martínez-Banderas Al, Aires A, Teran FJ, Perez JE, Cadenas JF, Alsharif N, et al. Functionalized magnetic nanowires for chemical and magnetomechanical induction of cancer cell death. Sci Rep. 2016:6:35786.

41. Reich DH, Tanase M, Hultgren A, Bauer LA, Chen CS, Meyer GJ. Biological applications of multifunctional magnetic nanowires (invited). J Appl Phys. 2003:93(10):7275-80.

42. Alfadhel A, Kosel J. Magnetic nanocomposite cilia tactile sensor. Adv Mater. 2015;27(47):7888-922.

43. Martinez-Banderas Al, Aires A, Quintanilla M, Holguin-Lerma JA, LozanoPedraza C, Teran FJ, et al. Iron-based core-shell nanowires for combinatorial drug delivery and photothermal and magnetic therapy. ACS Appl Mater Interfaces. 2019;11(47):43976-88.

44. Wang J, Sun J, Sun Q, Chen Q. One-step hydrothermal process to prepare highly crystalline $\mathrm{Fe}_{3} \mathrm{O}_{4}$ nanoparticles with improved magnetic properties. Mater Res Bull. 2003;38(7):1113-8.

45. Zhao D-L, Zeng X-W, Xia Q-S, Tang J-T. Preparation and coercivity and saturation magnetization dependence of inductive heating property of $\mathrm{Fe}_{3} \mathrm{O}_{4}$ nanoparticles in an alternating current magnetic field for localized hyperthermia. J Alloy Compd. 2009;469(1):215-8.

46. Darezereshki E, Bakhtiari F, Alizadeh M, Behrad A, Ranjbar M. Direct thermal decomposition synthesis and characterization of hematite $\left(a-\mathrm{Fe}_{2} \mathrm{O}_{3}\right)$ nanoparticles. Mater Sci Semiconduct Process. 2012;15(1):91-7.

47. Jose EP, Timothy $R$, Jürgen K. Mesenchymal stem cells cultured on magnetic nanowire substrates. Nanotechnology. 2017;28(5):055703.

48. Tojkander S, Gateva G, Lappalainen P. Actin stress fibers - assembly, dynamics and biological roles. J Cell Sci. 2012;125(8):1855.

49. Raphael MP, Christodoulides JA, Qadri SN, Simpkins BS, Byers JM. Magnetic moment degradation of nanowires in biological media: real-time monitoring with SQUID magnetometry. Nanotechnology. 2010;21(28):285101.

50. Liu Y, Li Y, Li X-M, He T. Kinetics of (3-Aminopropyl)triethoxylsilane (APTES) silanization of superparamagnetic iron oxide nanoparticles. Langmuir. 2013;29(49):15275-82.

51. Aires A, Ocampo SM, Cabrera D, de la Cueva L, Salas G, Teran FJ, et al. BSA-coated magnetic nanoparticles for improved therapeutic properties. J Mater Chem B. 2015:3(30):6239-47.

52. Margineanu MB, Julfakyan K, Sommer C, Perez JE, Contreras MF, Khashab $\mathrm{N}$, et al. Semi-automated quantification of living cells with internalized nanostructures. J Nanobiotechnol. 2016;14:13.

53. Arppe R, Nareoja T, Nylund S, Mattsson L, Koho S, Rosenholm JM, et al. Photon upconversion sensitized nanoprobes for sensing and imaging of pH. Nanoscale. 2014;6(12):6837-43.

54. Rohrer M, Bauer H, Mintorovitch J, Requardt M, Weinmann H-J. Comparison of magnetic properties of MRI contrast media solutions at different magnetic field strengths. Invest Radiol. 2005;40(11):715-24.

55. Kim H, Dae H-M, Park C, Kim EO, Kim D, Kim I-H, et al. A highly sensitive magnetite nanoparticle as a simple and rapid stem cell labelling agent for MRI tracking. J Mater Chem. 2011;21(21):7742-7.

56. Pöselt E, Kloust H, Tromsdorf $U$, Janschel M, Hahn C, Maßlo C, et al. Relaxivity optimization of a PEGylated iron-oxide-based negative magnetic resonance contrast agent for T2-weighted spin-echo imaging. ACS Nano. 2012;6(2):1619-24.

57. Ai H, Flask C, Weinberg B, Shuai X-T, Pagel MD, Farrell D, et al. Magnetiteloaded polymeric micelles as ultrasensitive magnetic-resonance probes. Adv Mater. 2005;17(16):1949-52.

58. Taktak S, Sosnovik D, Cima MJ, Weissleder R, Josephson L. Multiparameter magnetic relaxation switch assays. Anal Chem. 2007;79(23):8863-9.

59. Vuong QL, Gillis P, Gossuin Y. Monte Carlo simulation and theory of proton NMR transverse relaxation induced by aggregation of magnetic particles used as MRI contrast agents. J Magn Reson. 2011;212(1):139-48.

60. Roch A, Gossuin Y, Muller RN, Gillis P. Superparamagnetic colloid suspensions: Water magnetic relaxation and clustering. J Magn Magn Mater. 2005;293(1):532-9.
61. Hak S, Goa PE, Stenmark S, Bjerkholt FF, Haraldseth O. Transverse relaxivity of iron oxide nanocrystals clustered in nanoemulsions: Experiment and theory. Magn Reson Med. 2015;74(3):858-67.

62. Peng E, Wang F, Xue JM. Nanostructured magnetic nanocomposites as MRI contrast agents. J Mater Chem B. 2015;3(11):2241-76.

63. Vilanova Vidal E, Ivanov YP, Mohammed $H$, Kosel J. A detailed study of magnetization reversal in individual Ni nanowires. Appl Phys Lett. 2015;106(3):032403

64. Hertel R, Kirschner J. Magnetization reversal dynamics in nickel nanowires. Phys B. 2004;343(1-4):206-10.

65. Mohammed H, Moreno JA, Kosel J. Advanced fabrication and characterization of magnetic nanowires. Magnet Magnetic Mater. 2017;1:137-64.

66. Joshi HM, De M, Richter F, He JQ, Prasad PV, Dravid VP. Effect of silica shell thickness of $\mathrm{Fe}_{3} \mathrm{O}_{4}-\mathrm{SiOx}$ core-shell nanostructures on MRI contrast. J Nanoparticle Res. 2013;15:3.

67. LaConte LEW, Nitin N, Zurkiya O, Caruntu D, O'Connor CJ, Hu X, et al. Coating thickness of magnetic iron oxide nanoparticles affects $R 2$ relaxivity. J Magn Reson Imaging. 2007;26(6):1634-41.

68. Chen DX, Sun N, Huang ZJ, Cheng CM, Xu H, Gu HC. Experimental study on $\mathrm{T} 2$ relaxation time of protons in water suspensions of iron-oxide nanoparticles: Effects of polymer coating thickness and over-low 1/T2. J Magn Magn Mater. 2010;322(5):548-56.

69. Muller RN, Gillis P, Moiny F, Roch A. Transverse relaxivity of particulate MRI contrast media: from theories to experiments. Magn Reson Med. 1991;22(2):178-82.

70. Perez JE, Contreras MF, Vilanova E, Ravasi T, Kosel J. Cytotoxicity and Effects on Cell Viability of Nickel Nanowires. In: International conference on biological, medical and chemical engineering (Bmce 2013). 2013. p. 178-84.

71. Malak S, Yan MH, Guedeau-Boudeville MA, Conjeaud H, Garnier-Thibaud $\checkmark$, Boggetto $N$, et al. Interactions between magnetic nanowires and living cells: Uptake, toxicity and degradation. Abstr Papers Am Chem Soc. 2012;243:1

72. Perez JE, Contreras MF, Vilanova E, Felix LP, Margineanu MB, Luongo G, et al. Cytotoxicity and intracellular dissolution of nickel nanowires. Nanotoxicology. 2015;9(7):825-34.

73. de Schellenberger AA, Kratz H, Farr TD, Lowa N, Hauptmann R, Wagner S, et al. Labeling of mesenchymal stem cells for MRI with single-cell sensitivity. Int J Nanomed. 2016;11:1517-35.

74. Mazuel F, Espinosa A, Luciani N, Reffay M, Le Borgne R, Motte L, et al. Massive intracellular biodegradation of iron oxide nanoparticles evidenced magnetically at single-endosome and tissue levels. ACS Nano. 2016;10(8):7627-38

75. Shore D, Ghemes A, Dragos-Pinzaru O, Gao Z, Shao Q, Sharma A, et al. Nanowarming using Au-tipped Co(35)Fe(65) ferromagnetic nanowires. Nanoscale. 2019:11(31):14607-15.

76. Sharma A, Orlowski GM, Zhu YC, Shore D, Kim SY, DiVito MD, et al. Inducing cells to disperse nickel nanowires via integrin-mediated responses. Nanotechnology. 2015;26(13):12.

77. Seo HI, Cho AN, Jang J, Kim DW, Cho SW, Chung BG. Thermo-responsive polymeric nanoparticles for enhancing neuronal differentiation of human induced pluripotent stem cells. Nanomedicine. 2015;11(7):1861-9.

78. Dai R, Hang Y, Liu Q, Zhang S, Wang L, Pan Y, et al. Improved neural differentiation of stem cells mediated by magnetic nanoparticle-based biophysical stimulation. J Mater Chem B. 2019;7(26):4161-8.

79. Vissers $C$, Ming GL, Song $H$. Nanoparticle technology and stem cell therapy team up against neurodegenerative disorders. Adv Drug Deliv Rev. 2019;148:239-51.

80. Yi C, Liu D, Fong C-C, Zhang J, Yang M. Gold nanoparticles promote osteogenic differentiation of mesenchymal stem cells through p38 MAPK pathway. ACS Nano. 2010;4(11):6439-48.

\section{Publisher's Note}

Springer Nature remains neutral with regard to jurisdictional claims in published maps and institutional affiliations. 